\title{
DISSIMILARIDADE DE PORTA-ENXERTOS DA LARANJEIRA 'FOLHA MURCHA' SOB DOIS SISTEMAS DE MANEJO DE COBERTURA PERMANENTE DO SOLO ${ }^{(1)}$
}

\author{
Jonez Fidalski ${ }^{(2)}$, Carlos Alberto Scapim ${ }^{(3)} \&$ Neusa Maria \\ Colauto Stenzel ${ }^{(4)}$
}

\begin{abstract}
RESUMO
Os porta-enxertos de citros são dependentes do sistema de manejo do solo nas entrelinhas. Este trabalho foi realizado com o objetivo de identificar a dissimilaridade de sete porta-enxertos para a laranjeira 'Folha Murcha' em dois sistemas de manejo da cobertura de um Argissolo Vermelho distrófico latossólico. O estudo foi realizado na Estação Experimental do IAPAR, em Paranavaí. O delineamento experimental foi de blocos ao acaso com quatro repetições, com gramínea mato-grosso ou batatais (Paspalum notatum Flügge) em três blocos e leguminosa amendoim forrageiro (Arachis pintoi Krap. \& Greg.) em um bloco. A produção, o desenvolvimento vegetativo e os nutrientes nas folhas da laranjeira 'Folha Murcha' foram avaliados anualmente (1997 a 2002). As análises multivariadas basearam-se nas variáveis canônicas e nos componentes principais, agrupando-os pelo método Tocher. $\mathrm{O}$ manejo da cobertura do solo com a leguminosa amendoim forrageiro Arachis pintoi diminui a dissimilaridade dos grupos de portaenxertos da laranjeira 'Folha Murcha'. O manejo da cobertura do solo com a gramínea Paspalum notatum aumenta a dissimilaridade dos grupos de portaenxertos da laranjeira 'Folha Murcha' com a inclusão dos teores dos nutrientes foliares, da produção de frutos e do desenvolvimento vegetativo das plantas. A gramínea Paspalum notatum é o melhor sistema de manejo da cobertura do solo para avaliação do comportamento de porta-enxertos da laranjeira 'Folha Murcha'.
\end{abstract}

Termos de indexação: Citrus sinensis, manejo do solo, plantas de cobertura do solo, estado nutricional, análise multivariada.

\footnotetext{
(1) Recebido para publicação em maio de 2006 e aprovado em janeiro de 2007.

(2) Pesquisador do Instituto Agronômico do Paraná - IAPAR, Estação Experimental de Paranavaí. Caixa Postal 564, CEP 87701970 Paranavaí (PR). E-mail: fidalski@iapar.br

(3) Professor Adjunto da Universidade Estadual de Maringá - UEM. Departamento de Agronomia. Av. Colombo 5790, CEP 87020900 Maringá (PR). E-mail: cascapim@uem.br

(4) Pesquisadora do IAPAR, Caixa Postal 481, CEP 86001-970 Londrina (PR). E-mail: nstenzel@iapar.br
} 


\title{
SUMMARY: DIVERGENCE OF 'FOLHA MURCHA' ORANGE TREE ROOTSTOCKS AS INFLUENCED BY TWO GROUNDCOVER CROPS
}

\begin{abstract}
Citurs rootstocks are dependent of the growdcover management systems. This study aimed to identify the divergences of seven rootstocks for 'Folha Murcha' sweet orange trees in two groundcover management systems on a Paleudult. The study was performed at the IAPAR research station, in Paranavai, northwestern Paraná, Brazil. The experiment was in a complete random block design with threer replications for the bahiagrass (Paspalum notatum Flügge) groundcover treatment and one replication for the perennial groundnut legume (Arachis pintoi Krap. \& Greg.). Yield, vegetative growth and leaf nutrient contents were evaluated yearly in 'Folha Murcha' sweet orange trees (1997 to 2002). Multivariate analyses were based on canonic variables and main components, which were grouped according to the Tocher's method. The groundcover management with perennial peanut legume reduced the differences among rootstocks of 'Folha Murcha' orange trees. On the other hand, the groundcover management with bahiagrass increased the divergence among rootstocks regarding leaf nutrients, fruit yield and vegetative growth of orange trees. Bahiagrass is a preferable cover crop when aiming to evaluate the performance of grafted 'Folha Murcha' orange trees.
\end{abstract}

Index terms: Citrus sinensis, soil management, cover crops, nutritional status, multivariate analysis.

\section{INTRODUÇÃO}

O interesse comercial das indústrias de extração de suco do noroeste do Paraná pela laranjeira 'Folha Murcha' deve-se à ampliação do período de extração de suco, após as colheitas das laranjeiras 'Pêra' e 'Valência'. A carência de informação técnica sobre as melhores combinações de porta-enxertos tem condicionado o plantio de laranjeira 'Folha Murcha' enxertada principalmente sobre limoeiro 'Cravo' (Iapar, 1992).

O estudo regionalizado de porta-enxertos para a laranjeira 'Folha Murcha' é importante por considerar a interação entre genótipo e ambiente, confirmada experimentalmente por Stuchi et al. (2000) e Stenzel et al. (2005). O primeiro estudo apontou o limoeiro 'Volcameriano' como o porta-enxerto mais produtivo, e o segundo, o limoeiro 'Rugoso da África' e a tangerineira 'Cleópatra'.

O desenvolvimento de porta-enxertos e de herbicidas após a metade do século XX permitiu o adensamento das plantas nos pomares de laranjeiras (Kender, 2003). Inicialmente, o manejo da vegetação nas entrelinhas dos pomares com herbicida assegurou o potencial produtivo de inúmeras culturas permanentes, até ter sido constatada a degradação da qualidade do solo (Lipecki \& Berbeć, 1997).

A década de 1990 foi marcada pela retomada dos estudos de sistemas de manejo da cobertura vegetal permanente nas entrelinhas de citros no Brasil, restringindo a utilização de herbicida no controle da vegetação das linhas das plantas (Lipecki \& Berbeć, 1997). Nesse período, paralelamente à implantação de pomares de citros no Estado do Paraná, desenvolveram-se estudos de sistemas de manejo da cobertura com gramíneas e leguminosas permanentes (Fidalski et al., 1999).

Apesar de os experimentos com porta-enxertos possibilitarem a análise de muitas variáveis (Stuchi et al., 2000; Stenzel et al., 2005), são adotadas as análises de variância e o teste de separação de médias para cada uma das variáveis. Vislumbra-se a potencialidade de utilização de análises multivariadas nos estudos de porta-enxertos, a exemplo de Dantas et al. (2001), que, por meio dos componentes principais, agruparam 18 porta-enxertos de macieira em três grupos quanto à tolerância ao $\mathrm{Al}$ em solução nutritiva, e Theodoro et al. (2003), que agruparam as alterações químicas do solo nos sistemas de manejo orgânico e convencional de cafeeiro. A análise multivariada baseada nas análises canônicas também contribuiu para a separação de áreas de manejo com pínus (Baretta et al., 2005).

Nas décadas de 1980 e 1990, houve revisão internacional do manejo da vegetação nas entrelinhas de pomares de fruteiras de clima temperado, predominando as recomendações da manutenção das entrelinhas vegetadas com gramíneas, associadas às restrições do uso de herbicida localizado nas linhas das plantas (Hogue \& Neilsen, 1987; Lipecki \& Berbeæ, 1997). Dentre as gramíneas, Butler (1986) sugeriu o Paspalum notatum. Nesse período, em clima tropical, avaliava-se como alternativa de plantas de cobertura permanente do solo nas entrelinhas a leguminosa amendoim forrageiro (Arachis pintoi) em bananeira, tangerineira e laranjeira (Johns, 1994; Neves et al.,1998; Fidalski et al., 1999; Dalcolmo et al., 1999). 
Estudos envolvendo o desenvolvimento e a produção de frutos das variedades copas e porta-enxertos em diferentes condições ambientais poderiam melhorar as práticas de manejo em citros com os porta-enxertos. O presente estudo teve o objetivo de identificar a dissimilaridade entre os grupos de porta-enxertos para a laranjeira 'Folha Murcha' em dois sistemas de manejo da cobertura do solo (gramínea e leguminosa), nas condições edafoclimáticas do noroeste do Paraná, com base em análises multivariadas das variáveis produção, número de frutos, desenvolvimento vegetativo e nutrientes das folhas da laranjeira 'Folha Murcha'.

\section{MATERIAL E MÉTODOS}

O estudo foi realizado no período de 1997 a 2002, na Estação Experimental de Paranavaí, do Instituto Agronômico do Paraná - IAPAR, no município de Paranavaí, noroeste do Paraná (23도 ' S, $52^{\circ} 26^{\prime}$ W, altitude $480 \mathrm{~m}$ ), em um experimento de plantas de laranjeiras 'Folha Murcha' [Citrus sinensis (L.) Osb.] enxertadas em sete porta-enxertos, implantado em dezembro de 1988. O clima é subtropical (Cfa), com concentração de chuvas no verão e precipitações anuais de $1.500 \mathrm{~mm}$, sem estação seca definida (Iapar, 2000). O solo corresponde a Argissolo Vermelho distrófico latossólico textura areia/franco-arenosa A moderado relevo suave ondulado (Quadro 1) (Embrapa, 1999).

O delineamento experimental utilizado foi de blocos ao acaso, com quatro repetições. As parcelas experimentais apresentavam três plantas em linhas, espaçadas em $4 \mathrm{~m}$, e entrelinhas, em $7 \mathrm{~m}$. Foram avaliados os seguintes porta-enxertos: (a) limoeiro 'Cravo' (Citrus limonia Osb.); (b) limoeiro 'Rugoso da África' (Citrus jambhiri Lush.); (c) limoeiro 'Volcameriano' (Citrus volkameriana Ten. e Pasq.); (d) tangerineira 'Cleópatra' (Citrus reshni Hort. ex Tan.); (e) tangerineira 'Sunki' (Citrus sunki Hort. ex Tan.); (f) citrangeiro 'C-13' [(Citrus sinensis (L.) Osb. x Poncirus trifoliata (L.) Raf.)]; e (g) trifoliata [Poncirus trifoliata (L.) Raf.].
No período de 1988 a 1995, predominava a cobertura das entrelinhas das laranjeiras com a grama matogrosso ou batatais (Paspalum notatum Flügge). Em 1996, em um dos quatro blocos foi implantada a leguminosa amendoim forrageiro (Arachis pintoi Krap. \& Greg.), nas entrelinhas das laranjeiras (Ribeiro, 1996).

No período de 1996 a 1999, foi distribuído calcário na superfície do solo em área total, equivalente à aplicação anual de 3 t ha ${ }^{-1}$ de calcário dolomítico, para elevar a saturação por bases a 70 \%. A adubação mineral de solo foi feita em cada safra agrícola com $180 \mathrm{~kg} \mathrm{ha}^{-1}$ de $\mathrm{N}, 75$ de $\mathrm{P}_{2} \mathrm{O}_{5}$ e 140 de $\mathrm{K}_{2} \mathrm{O}$, respectivamente, com sulfato de amônio, superfosfato simples e cloreto de potássio, parceladas nos bimestres de agosto-setembro, outubro-novembro e fevereiromarço, à exceção do superfosfato simples, que foi aplicado em dose única no primeiro bimestre. Nesses bimestres foram também realizadas aplicações foliares à base de macronutrientes e micronutrientes com produtos comerciais para citros, variando entre uma a três pulverizações por safra agrícola. Nas linhas das plantas, o controle da vegetação foi feito com herbicida (Glyphosate), e o da vegetação permanente das entrelinhas, com roçadas mecânicas, realizadas conforme a necessidade desses manejos culturais.

$\mathrm{O}$ crescimento vegetativo das plantas (altura e diâmetro da copa) foi obtido nos invernos de 1996-2002, utilizando-se uma régua métrica; a altura foi tomada desde a superfície do solo até o topo da planta, e o diâmetro da copa, medido no sentido paralelo e perpendicular à linha de plantio. $\mathrm{O}$ volume da copa foi determinado pela fórmula de Mendel (1956), $\left[\mathrm{V}=2 / 3 \pi \mathrm{r}^{2} \mathrm{~h}\right.$ ], em que: $\mathrm{V}$ é o volume da copa $\left(\mathrm{m}^{3}\right) ; \mathrm{r}$, o raio da copa (m); e h, altura da planta $(\mathrm{m})$. A produção de frutos e o número destes foram obtidos de outubro a dezembro de 1997 a 2002, correspondendo a seis safras agrícolas (1996/1997 a 2001/2002).

O estado nutricional das plantas foi obtido por meio de amostras foliares coletadas no verão (janeiro-março) de 1997 a 2002, coletando-se a terceira e a quarta folha em ramos com frutos verdes nas extremidades, geradas na primavera (6 a 8 meses de idade), na altura mediana e nos quatro quadrantes da copa das três

Quadro 1. Granulometria e classe textural dos horizontes do Argissolo Vermelho distrófico latossólico

\begin{tabular}{|c|c|c|c|c|c|}
\hline Horizonte & Profundidade & Argila & Silte & Areia & Classe textural \\
\hline & $\mathrm{m}$ & 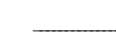 & $-\mathrm{g} \mathrm{kg}^{-1}$ & 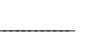 & \\
\hline $\mathrm{A}$ & $0-0,16$ & $80^{(1)}$ & 20 & 900 & Areia $^{(2)}$ \\
\hline $\mathrm{Bt}$ & $0,17-0,48$ & 176 & 20 & 804 & Franco-arenosa \\
\hline $\mathrm{Bw}$ & $0,49-2,00$ & 167 & 10 & 823 & Franco-arenosa \\
\hline
\end{tabular}

\footnotetext{
${ }^{(1)}$ Método do hidrômetro de Bouyoucos (Gee \& Or, 2002). (2) Santos et al. (1993).
} 
plantas, em cada uma das parcelas experimentais, de acordo com a recomendação do Grupo Paulista de Adubação e Calagem para Citros (1994). As folhas foram lavadas com solução de ácido clorídrico a 3 \% e água destilada, como sugerido por Miyazawa et al. (1992). A extração de $\mathrm{N}$ e $\mathrm{P}$ foi realizada por meio da digestão sulfúrica, e a de $\mathrm{Ca}, \mathrm{Mg}, \mathrm{K}, \mathrm{B}, \mathrm{Zn}$ e $\mathrm{Mn}$, por meio da digestão com $\mathrm{HCl} 1 \mathrm{~mol} \mathrm{~L}^{-1}$. As determinações analíticas utilizadas foram a colormetria $(\mathrm{N}$, $\mathrm{P}$ e B), fotometria (K) e espectrometria de absorção atômica (Ca, $\mathrm{Mg}, \mathrm{Mn}, \mathrm{Cu}$ e $\mathrm{Zn}$ ), conforme detalhes descritos por Miyazawa et al. (1992). Para os elementos $\mathrm{S}$ e $\mathrm{Fe}$, a amostra de tecido vegetal foi digerida com a solução $\left(\mathrm{HNO}_{3}+\mathrm{HClO}_{4}\right)$, em sistema aberto, sendo eles determinados por absorção atômica.

Para obtenção das matrizes com as médias e os resíduos necessários às análises multivariadas, foi utilizado o delineamento experimental de blocos ao acaso, no sistema de manejo da cobertura do solo com gramínea-leguminosa (três blocos com gramínea e um bloco com leguminosa) e gramínea (três blocos). No sistema de manejo da cobertura do solo com leguminosa utilizou-se o delineamento experimental inteiramente casualizado, com sete porta-enxertos e seis repetições (1997 a 2002).

As análises estatísticas das variáveis canônicas e dos componentes principais consistem na transformação de um conjunto de variáveis, por meio da combinação linear, com dimensões equivalentes em dois eixos ortogonais não-correlacionados, representando os componentes principais $(\mathrm{C} 1$ e $\mathrm{C} 2)$ ou variáveis canônicas ( $\mathrm{VC} 1$ e $\mathrm{VC} 2)$, desde que envolva $80 \%$ da variação total, permitindo o agrupamento dos tratamentos, graficamente, do primeiro eixo na abscissa (C1 ou VC1) e do segundo eixo na ordenada (C2 e VC2) (Cruz et al., 2004). O método de agrupamento utilizado foi o de ligação média entre grupos (UPMGA) para ambos os sistemas de manejo da cobertura do solo, especificando o procedimento da distância euclidiana média (leguminosa) e distância de Mahalanobis (gramínea-leguminosa e gramínea), enquanto as análises de grupos foram realizadas pelo método de Tocher comum aos dois sistemas de manejo da cobertura do solo, de acordo com Cruz et al. (2004). Nas análises estatísticas foi utilizado o programa GENES (Cruz, 2001).

As variáveis foram avaliadas e estudadas em três fases: (a) cinco variáveis - produção, número de frutos e desenvolvimento vegetativo das plantas; (b) 11 variáveis - teores de nutrientes foliares; e (c) 16 variáveis - produção, número de frutos, desenvolvimento vegetativo das plantas e teores de nutrientes foliares. Os números de variáveis submetidas às análises multivariadas foram distintos nos dois sistemas de manejo da cobertura do solo: 13,15 e 16, nos sistemas de manejo da cobertura do solo leguminosa, gramínealeguminosa e gramínea, respectivamente. No sistema de manejo da cobertura do solo com leguminosa houve necessidade da transformação dos dados para distribuição lognormal (ln) para as variáveis (diâmetro, altura, $\mathrm{Cu}$ e B). As variáveis $\mathrm{S}, \mathrm{Zn}$ e $\mathrm{Fe}$ (leguminosa) e altura das plantas (gramínealeguminosa) não foram submetidas às análises multivariadas porque não atenderam aos pressupostos básicos de normalidade dos resíduos das amostras.

\section{RESULTADOS E DISCUSSÃO}

Produção, número de frutos e desenvolvimento das laranjeiras 'Folha Murcha' revelaram baixa variabilidade dos dados, considerando o coeficiente de variação, à exceção do número de frutos das laranjeiras no sistema de manejo da cobertura do solo com leguminosa (Quadro 2). Os porta-enxertos limoeiro 'Rugoso da Africa' e tangerineira 'Cleópatra' apresentaram valores superiores aos da média de produção, número de frutos e desenvolvimento das laranjeiras nos sistemas de manejo da cobertura do solo gramínea e leguminosa, observando-se o contrário para o porta-enxerto trifoliata. Essa análise exploratória confirma os resultados obtidos por Stenzel et al. (2005), quanto aos dois porta-enxertos mais promissores para a laranjeira 'Folha Murcha' em sistemas de manejo da cobertura do solo com gramínea e leguminosa.

A concentração dos nutrientes das folhas das laranjeiras 'Folha Murcha' apresentou maior variabilidade para $\mathrm{Mn}$ no sistema de manejo da cobertura do solo com gramínea e para $\mathrm{S}, \mathrm{Zn}, \mathrm{Mn}, \mathrm{Cu}$ e Fe com leguminosa (Quadro 3). De acordo com o Grupo Paulista de Adubação e Calagem para os Citros (1994), os teores médios de P e Zn apresentaram teores baixos; $\mathrm{N}, \mathrm{Mg}, \mathrm{S}, \mathrm{B}$ e Fe, teores adequados; $\mathrm{Mn}$ e $\mathrm{Cu}$, teores excessivos; $\mathrm{K}$, teores baixos e adequados; e Ca, teores adequados, considerando-se o nível crítico de 29,72 $\mathrm{g} \mathrm{kg}^{-1}$ (Fidalski et al., 1999).

A análise multivariada dos sistemas de manejo da cobertura do solo gramínea-leguminosa mostrou dissimilaridade dos porta-enxertos da laranjeira 'Folha Murcha' em dois grupos para as variáveis produção, número de frutos e desenvolvimento vegetativo com ou sem as variáveis dos teores de nutrientes foliares (Figuras 1, 2 e 3). Pela análise dos dados, pode-se observar a distinção de dois grupos: grupo I (limoeiro 'Cravo', limoeiro 'Rugoso da África', limoeiro 'Volcameriano', tangerineira 'Cleópatra', tangerineira 'Sunki' e citrangeiro 'C-13') e grupo II (trifoliata). A dissimilaridade dos grupos de porta-enxertos da laranjeira 'Folha Murcha' tornou-se mais evidente para o manejo da cobertura do solo com gramínea em relação à leguminosa, com exceção dos teores de nutrientes foliares (Figuras 1, 2 e 3), indicando a influência do manejo da cobertura do solo nos estudos de porta-enxertos e sistema de manejo do solo, como também foi observado por Dantas et al. (2001), Theodoro et al. (2003) e Baretta et al. (2005). 
Quadro 2. Produção, número de frutos, altura, diâmetro e volume da copa das plantas de laranjeira 'Folha murcha' enxertada sobre sete porta-enxertos e dois sistemas de manejo da cobertura do solo com vegetação gramínea (G) e leguminosa (L)

\begin{tabular}{|c|c|c|c|c|c|c|c|c|c|c|}
\hline \multirow[b]{2}{*}{ Porta-enxerto } & \multicolumn{2}{|c|}{ Produção } & \multicolumn{2}{|c|}{ Fruto } & \multicolumn{2}{|c|}{ Altura } & \multicolumn{2}{|c|}{ Diâmetro } & \multicolumn{2}{|c|}{ Volume } \\
\hline & $\mathbf{G}^{(1)}$ & $\mathbf{L}^{(2)}$ & $G^{(1)}$ & $\mathbf{L}^{(2)}$ & $\mathbf{G}^{(2)}$ & $\mathbf{L}^{(2)}$ & $\mathbf{G}^{(2)}$ & $\mathbf{L}^{(2)}$ & $\mathbf{G}^{(2)}$ & $\mathbf{L}^{(2)}$ \\
\hline & \multicolumn{2}{|c|}{ - kg/planta - } & \multicolumn{2}{|c|}{ - Número - } & \multicolumn{2}{|c|}{$\longrightarrow$} & & - & \multicolumn{2}{|c|}{$\mathrm{m}^{3}$} \\
\hline Limoeiro 'Cravo' & 607 & 77 & 3.545 & 489 & 3,5 & 3,6 & 3,4 & 3,5 & 20,9 & 23,4 \\
\hline Limoeiro 'Rugoso da África' & 740 & 123 & 4.398 & 734 & 3,8 & 3,8 & 3,8 & 3,8 & 28,4 & 28,6 \\
\hline Limoeiro 'Volcameriano' & 459 & 90 & 3.007 & 538 & 3,1 & 3,1 & 3,2 & 3,4 & 16,6 & 19,7 \\
\hline Tangerineira 'Cleópatra' & 741 & 115 & 4.266 & 653 & 3,8 & 3,9 & 3,7 & 3,8 & 28,6 & 29,6 \\
\hline Tangerineira 'Sunki' & 545 & 86 & 3.392 & 517 & 3,5 & 3,4 & 3,4 & 3,4 & 21,2 & 20,9 \\
\hline Citrangeiro 'C-13' & 601 & 102 & 3.988 & 607 & 3,6 & 3,6 & 3,4 & 3,5 & 21,5 & 22,8 \\
\hline Trifoliata & 329 & 55 & 2.136 & 346 & 2,8 & 3,2 & 2,6 & 2,6 & 10,3 & 11,4 \\
\hline Média & 575 & 92 & 3.533 & 555 & 3,4 & 3,5 & 3,4 & 3,4 & 21,1 & 22,3 \\
\hline Coeficiente de variação (\%) & 10 & 27 & 9 & 30 & 3,4 & 3,8 & 4,2 & 2,1 & 10,6 & 2,6 \\
\hline
\end{tabular}

(1) Valor acumulado nas seis safras agrícolas (1997-2002). ${ }^{(2)}$ Valor médio de seis safras agrícolas (1997-2002).

Quadro 3. Teores médios de nutrientes nas folhas de laranjeira 'Folha Murcha' enxertada sobre sete portaenxertos e dois sistemas de manejo da cobertura do solo

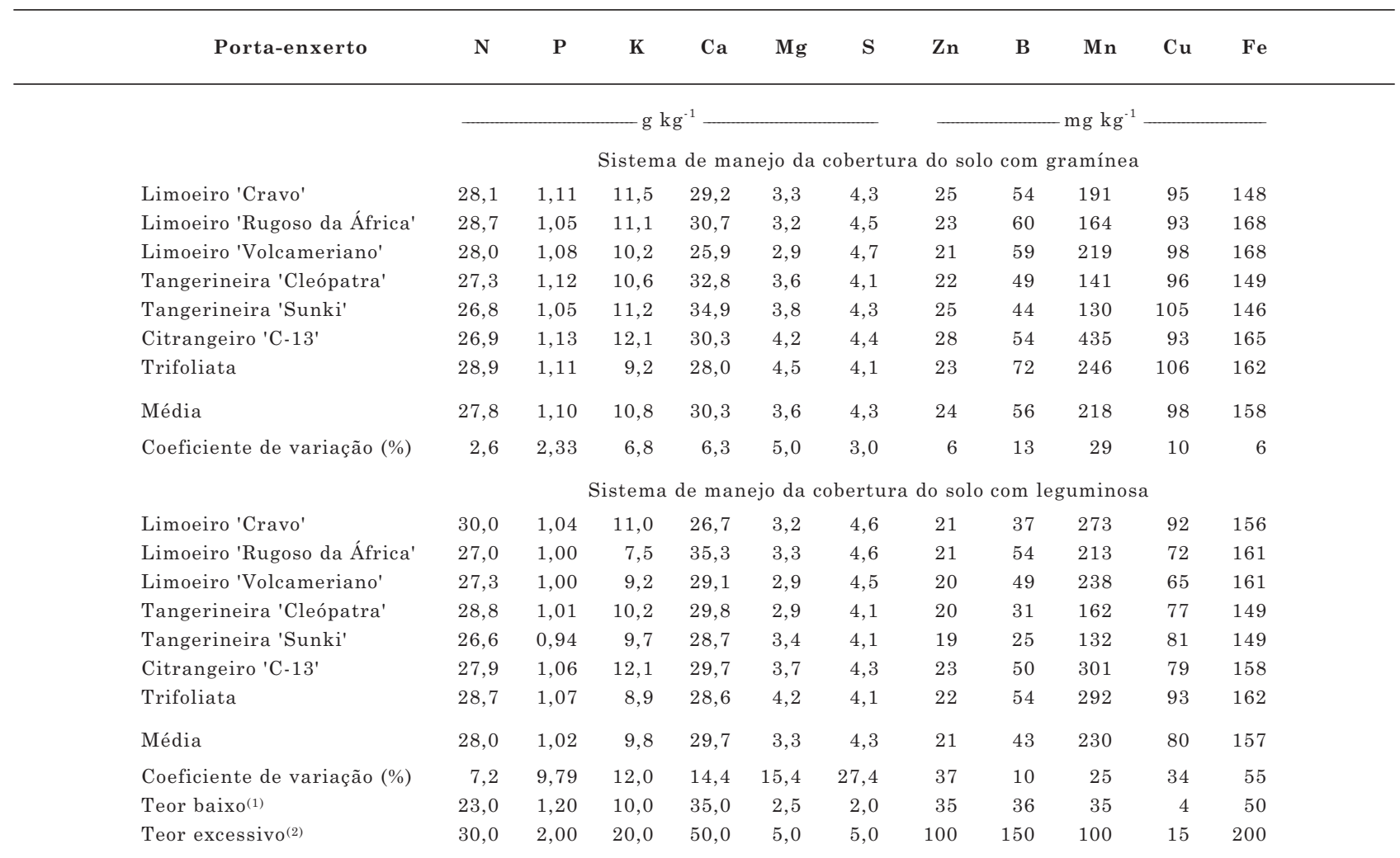

(1) $\mathrm{e}^{(2)}$ Teores de nutrientes baixo e excessivo, respectivamente inferiores e superiores aos valores referenciais do Grupo Paulista de Adubação e Calagem para Citros (1994).

Independentemente da cobertura do solo na entrelinha, observa-se distinção na produção, número de frutos e desenvolvimento vegetativo das plantas entre os porta-enxertos em dois grupos, com similaridade entre os porta-enxertos limoeiro ('Cravo' e 'Rugoso da África'), tangerineira ('Sunki' e 'Cleópatra') 
e citrangeiro 'C-13', os quais se diferenciaram do portaenxerto trifoliata (Figura 1). Nesta figura observa-se que o porta-enxerto 'Volcameriano' foi dependente do sistema de manejo da cobertura do solo. Este portaenxerto no sistema de manejo da cobertura do solo com gramínea foi semelhante ao porta-enxerto trifoliata. Esses resultados confirmam estatisticamente as respostas dessas variáveis, como também foi observado por Stenzel et al. (2005), quanto ao menor vigor vegetativo e menor produção dos portaenxertos 'Volcameriano' e trifoliata (Quadro 2).

$\mathrm{O}$ estado nutricional das plantas de laranjeira 'Folha Murcha' apresentou maior dissimilaridade do número de grupos de porta-enxertos - três e quatro, respectivamente, nos sistemas de manejo da cobertura do solo com gramínea e com leguminosa (Figura 2). Os porta-enxertos limoeiro 'Cravo', tangerineira
'Cleópatra' e limoeiro 'Volcameriano' mostraram similaridade nos dois sistemas de manejo da cobertura do solo, ao mesmo tempo em que esse grupo distinguiuse dos porta-enxertos citrangeiro 'C $\mathrm{C}$-13' e trifoliata (Figura 2). Esse padrão de dissimilaridade de grupos de porta-enxerto de acordo com os sistemas de manejo da cobertura do solo caracteriza a gramínea como melhor indicador de estratificação de porta-enxertos para a laranjeira 'Folha Murcha' nesses solos, quando comparada à leguminosa, que diferenciou outros dois grupos: (limoeiro 'Rugoso da África' e tangerineira 'Sunki') e (limoeiro 'Cravo', limoeiro 'Volcameriano', tangerineira 'Cleópatra', citrangeiro 'C-13' e trifoliata). Possivelmente, isso se deve à menor fertilidade desses solos quando se mantém a vegetação permanente nas entrelinhas do pomar de laranjeira com esta leguminosa (Fidalski et al., 1999; Fidalski \& Stenzel, 2006).
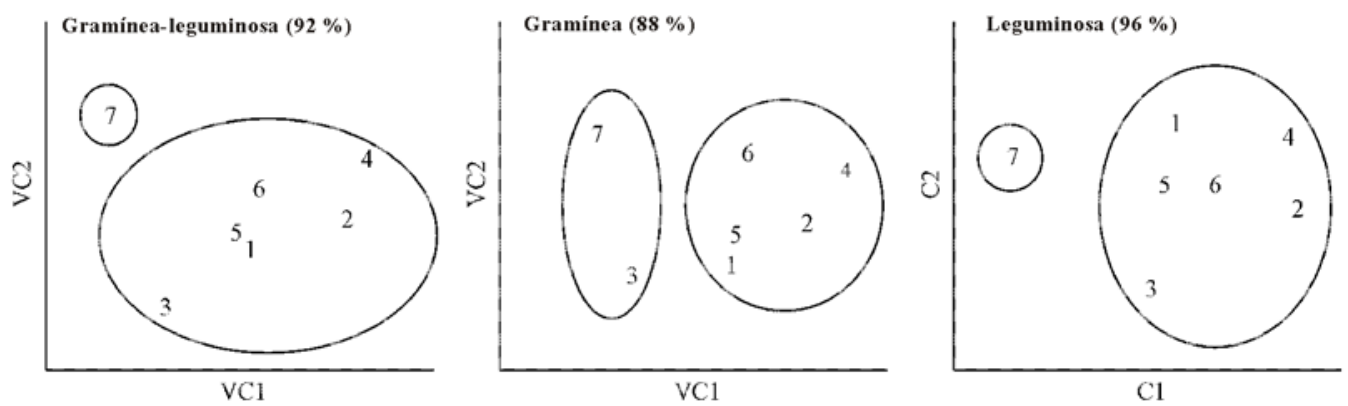

Figura 1. Dispersão dos sete porta-enxertos em relação às duas variáveis canônicas (VC1 e VC2) e aos dois primeiros componentes principais (C1 e C2), agrupados pelo método de Tocher (círculos e elipses), para produção, número de frutos e desenvolvimento vegetativo das plantas da laranjeira 'Folha Murcha', em sistemas de manejo da cobertura do solo com gramínea-leguminosa, gramínea e leguminosa. Portaenxertos: 1 - (limoeiro 'Cravo'), 2 - (limoeiro 'Rugoso da África'), 3 - (limoeiro 'Volcameriano'), 4 - (tangerineira 'Cleópatra'), 5 - (tangerineira 'Sunki'), 6 - (citrangeiro 'C-13') e 7 - (trifoliata). Os percentuais dentro dos parênteses correspondem aos valores dos dois primeiros autovalores.
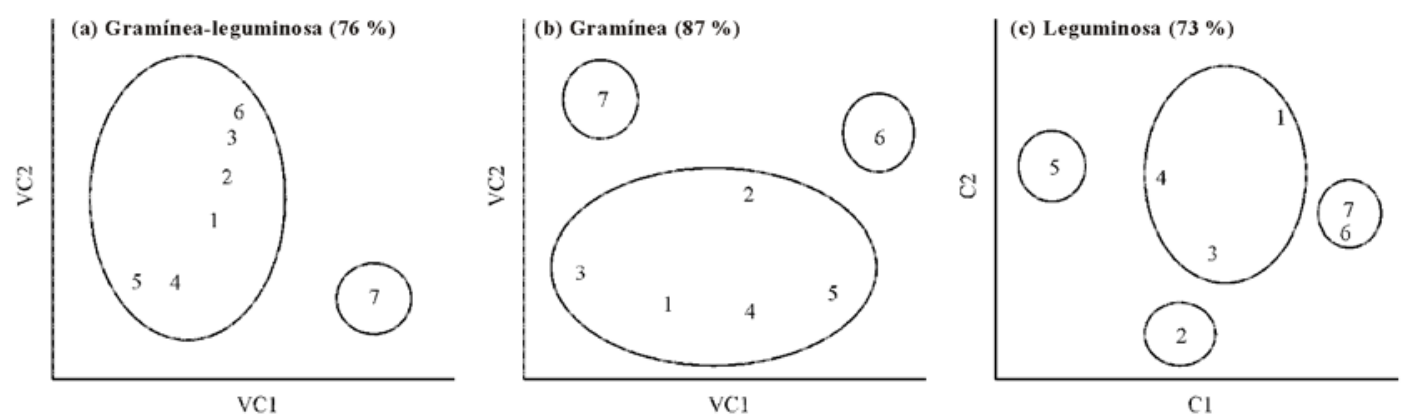

Figura 2. Dispersão dos sete porta-enxertos em relação às duas variáveis canônicas (VC1 e VC2) e aos dois primeiros componentes principais (C1 e C2), agrupados pelo método de Tocher (círculos e elipses), para os teores de nutrientes foliares das laranjeiras 'Folha Murcha', em sistemas de manejo da cobertura do solo com gramínea-leguminosa, gramínea e leguminosa. Porta-enxertos: 1 - (limoeiro 'Cravo'), 2 (limoeiro 'Rugoso da África'), 3 - (limoeiro 'Volcameriano'), 4 - (tangerineira 'Cleópatra'), 5 - (tangerineira 'Sunki'), 6 - (citrangeiro 'C-13') e 7 - (trifoliata). Os percentuais dentro dos parênteses correspondem aos valores dos dois primeiros autovalores. 

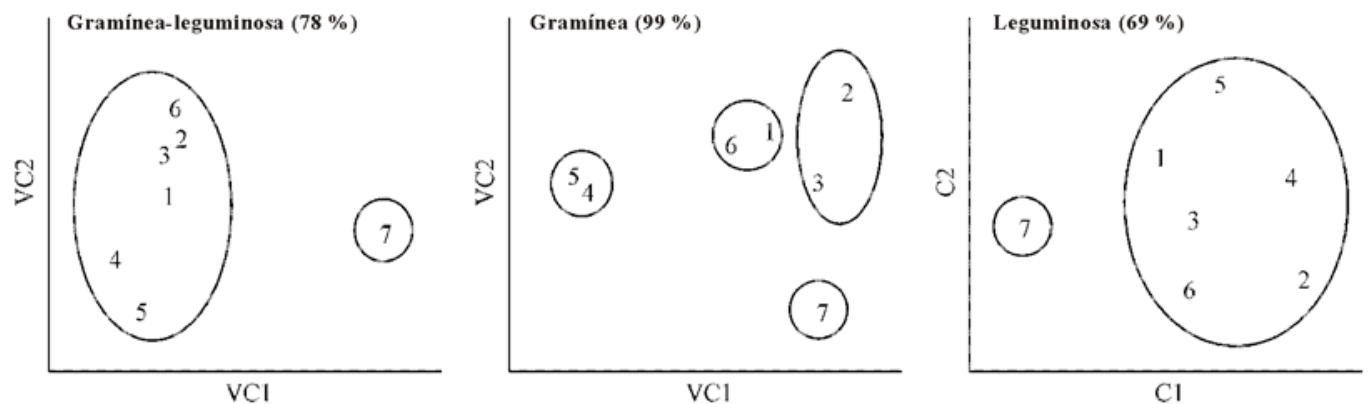

Figura 3. Dispersão dos sete porta-enxertos em relação às duas variáveis canônicas (VC1 e VC2) e aos dois primeiros componentes principais (C1 e C2), agrupados pelo método de Tocher (círculos e elipses), para as variáveis produção, número de frutos, desenvolvimento vegetativo e teores de nutrientes foliares das laranjeiras 'Folha Murcha', em sistemas de manejo da cobertura do solo com gramínea-leguminosa, gramínea e leguminosa. Porta-enxertos: 1 - (limoeiro 'Cravo'), 2 - (limoeiro 'Rugoso da África'), 3 - (limoeiro 'Volcameriano'), 4 - (tangerineira ‘Cleópatra'), 5 - (tangerineira 'Sunki'), 6 - (citrangeiro 'C-13') e 7 - (trifoliata). Os percentuais dentro dos parênteses correspondem aos valores dos dois primeiros autovalores.

A dispersão dos sete porta-enxertos com base nas variáveis canônicas e nos componentes principais (Figuras 1, 2 e 3) revelou diferenciação dos sistemas de manejo da cobertura do solo no agrupamento dos porta-enxertos com a adição das variáveis dos nutrientes foliares às variáveis de produção, número de frutos e crescimento vegetativo das plantas. A expectativa de acrescentar o maior número possível de variáveis para aumentar o número de grupos com a finalidade de distinguir os porta-enxertos foi pertinente somente para o sistema de manejo da cobertura do solo com gramínea, o que é confirmado pelo aumento da explicação dos dois primeiros autovalores das variáveis canônicas (88, 87 e 99 \%). Contrariamente, os dois primeiros autovalores dos componentes principais no sistema de manejo da cobertura do solo com leguminosa decresceram (96, 73 e 69 \%) (Figuras 1, 2 e 3).

A contribuição científica da resposta do conjunto das características agronômicas, representada pelos dois autovalores dos componentes principais e pelas variáveis canônicas na dissimilaridade dos grupos de porta-enxertos para a laranjeira 'Folha Murcha' entre os sistemas de manejo da cobertura do solo com gramínea e leguminosa (Figuras 1, 2 e 3), é respaldada tecnicamente pelos resultados, que indicam menor qualidade física e maior restrição hídrica deste solo sob o manejo da entrelinha com a leguminosa Arachis pintoi, comparada à gramínea Paspalum notatum (Fidalski, 2004).

Considerando-se os resultados das análises multivariadas (Figura 3), das análises de variância e teste de separação de médias das variáveis produção, número de frutos e desenvolvimento vegetativo das plantas (Stenzel et al., 2005), a qualidade do solo (Fidalski, 2004) e o predomínio do sistema de manejo da cobertura do solo com gramínea no noroeste do Paraná (Fidalski \& Auler, 1997), os porta-enxertos para a laranjeira 'Folha Murcha', nas condições edafoclimáticas desta região com gramínea, podem ser classificados na seguinte ordem decrescente de importância agronômica: grupo I (tangerineira 'Cleópatra' e tangerineira 'Sunki'), grupo II (limoeiro 'Rugoso da África' e limoeiro 'Volcameriano'), grupo III (limoeiro 'Cravo' e citrangeiro 'C-13') e grupo IV (trifoliata).

As análises multivariadas baseadas nas variáveis canônicas e nos componentes principais comprovaram a dependência dos porta-enxertos em relação aos sistemas de manejo nas entrelinhas do pomar de laranjeira 'Folha Murcha'. O conhecimento gerado com este estudo corrobora a diversificação dos portaenxertos de acordo com o sistema de manejo da cobertura do solo com gramínea.

\section{CONCLUSÕES}

1. O manejo da cobertura do solo com a leguminosa amendoim forrageiro Arachis pintoi diminui a dissimilaridade dos grupos de porta-enxertos da laranjeira 'Folha Murcha'.

2. O manejo da cobertura do solo com a gramínea Paspalum notatum aumenta a dissimilaridade dos grupos de porta-enxertos da laranjeira 'Folha Murcha' com a inclusão dos teores dos nutrientes foliares da produção de frutos e do desenvolvimento vegetativo das plantas.

3. A gramínea Paspalum notatum é o melhor sistema de manejo da cobertura do solo para avaliação do comportamento de porta-enxertos da laranjeira 'Folha Murcha'.

\section{LITERATURA CITADA}

BARETTA, D.; SANTOS, J.C.P.; FIGUEIREDO, S.R. \& KLAUBERG-FILHO, O. Efeito do monocultivo de pinus e da queima do campo nativo em atributos biológicos do solo no planalto catarinense. R. Bras. Ci. Solo, 29:715724,2005 . 
BUTLER, J.D. Grass interplanting in horticulture cropping systems. Hort Sci., 21:394-397, 1986.

CRUZ, C.D. Programa GENES - versão windows. Viçosa, MG, Universidade Federal de Viçosa, 2001. 642p. (Versão 2005.0.0)

CRUZ, C.D.; REGAZZI, A.J. \& CARNEIRO, P.C.S. Modelos biométricos aplicados ao melhoramento genético. 3.ed. Viçosa, MG, Universidade Federal de Viçosa, 2004. 480p.

DALCOLMO, J.M.; ALMEIDA, D.L. \& GUERRA, J.G.M. Avaliação de leguminosas perenes para cobertura de solo em pomar cítrico no município de Jerônimo Monteiro, ES. Seropédica, Embrapa, 1999, 8p. (Embrapa Agrobiologia. Comunicado Técnico, 36)

DANTAS, A.C.M.; FORTES, G.R.L.; SILVA, J.B.; NEZI, A.N \& RODRIGUES, A.C. Tolerância ao alumínio em portaenxertos somaclonais de macieira cultivados em solução nutritiva. Pesq. Agropec. Bras., 36:615-623, 2001.

EMPRESA BRASILEIRA DE PESQUISA AGROPECUÁRIA . EMBRAPA. Sistema brasileiro de classificação de solos. Rio de Janeiro, Embrapa Solos, 1999. 412p.

FIDALSKI, J.; PAVAN, M.A.; AULER, P.A.M. \& JACOMINO, A.P. Produção de frutos de laranjeira Pêra e teores de nutrientes nas folhas e no solo, em Latossolo VermelhoEscuro do noroeste do Paraná. R. Bras. Ci. Solo, 23:273$279,1999$.

FIDALSKI, J. \& AULER, P.A.M. Levantamento nutricional de pomares de laranja no noroeste do Paraná. Arq. Biol. Tecnol., 40:443-451, 1997.

FIDALSKI, J. \& STENZEL, N.M.C. Nutrição e produção da laranjeira "Folha Murcha" em porta-enxertos e plantas de cobertura permanente na entrelinha. Ci. Rural, 36:807 813, 2006.

FIDALSKI, J. Propriedades físico-hídricas de um Argissolo Vermelho distrófico latossólico em diferentes sistemas de manejo das entrelinhas de citros, Maringá, Universidade Estadual de Maringá, 2004. 62p. (Tese de Mestrado)

GEE, G.W. \& OR, D. Particle-size analysis. In: DANE, J.H. \& TOPP, C. eds. Methods of soil analysis: Physical methods. Madison, Soil Science Society of America, 2002. v.4, p.255293

GRUPO PAULISTA DE ADUBAÇÃO E CALAGEM PARA CITROS. Recomendações de adubação e calagem para citros no Estado de São Paulo, 3.ed. Laranja, Edição Especial, 1994. 27p.
HOGUE, E.J. \& NEILSEN, G.H. Orchard floor vegetation management. Hortic. Rev., 9:377-430, 1987.

INSTITUTO AGRONÔMICO DO PARANÁ- IAPAR. A citricultura no Paraná. Londrina, IAPAR, 1992. 288p. (IAPAR, Circular, 72)

INSTITUTO AGRONÔMICO DO PARANÁ- IAPAR. Cartas climáticas do Paraná: Edição ano 2000, versão 1.0. Londrina, IAPAR, 2000. CD-ROM

JOHNS, G.G. Effects of Arachis pintoi groundcover on performance of bananas in Northern New South Wales. Aust. J. Exp. Agric., 34:1197-1204, 1994.

KENDER, W.J. Citrus. Hortsciense, 38:1043-1047, 2003.

LIPECKI, J. \& BERBEÆ, S. Soil management in perennial crops: Orchards and hop gardens. Soil Till. Res., 43:169184, 1997.

MENDEL, K. Rootstock-scion relations in Shamouti trees on light soil. Ktavim, 6:35-60, 1956.

MIYAZAWA, M.; PAVAN, M.A. \& BLOCH, M.F. Análise química de tecido vegetal. Londrina, IAPAR, 1992. 17p. (IAPAR. Circular, 74)

RIBEIRO, P.G.F. Viabilidade da implantação de Arachis pintoi por estolões para cobertura verde em pomar de citros. In: CONGRESSO BRASILEIRO DE FRUTICULTURA, 14., Curitiba, 1996. Resumos. Londrina, IAPAR, 1996. p.176.

NEVES, C.S.V.J.; DECHEN, A.R.; FELLER, C.; SAAB, O.J.G. \& PIEDADE, S.M.S. Efeito do manejo do solo no sistema radicular de tangerineira 'Poncã' enxertada sobre limoeiro 'Cravo' em Latossolo Roxo. R. Bras. Frutic., 20:246-253, 1998.

SANTOS, R.D.; LEMOS, R.C.; SANTOS, H.G.; KER, J.C. \& ANJOS, L.H.C. Manual de descrição e coleta de solo no campo. 5.ed. Viçosa, MG, Sociedade Brasileira de Ciência do Solo, 2005. p.17-21

STENZEL, N.M.C.; NEVES, C.S.V.J.; SCHOLZ, M.B.S. \& GOMES, J.C. Comportamento da laranjeira "Folha Murcha" em sete porta-enxertos no noroeste do Paraná R. Bras. Frutic., 27:408-411, 2005.

STUCHI, E.S.; DONADIO, L.C. \& SEMPIONATO, O.R. Avaliação da laranjeira 'Folha Murcha' (Citrus sinensis (L) Osbeck) sobre dez porta-enxertos em Bebedouro, SP. R. Bras. Frutic., 2:446-453, 2000.

THEODORO, V.C.A.; ALVARENGA, M.I.N.; GUIMARÃES, R.J. \& SOUZA, C.A.S. Alterações químicas em solo submetido a diferentes formas de manejo do cafeeiro. R. Bras. Ci. Solo, 27:1039-1047, 2003. 